\title{
Enfermedad tromboembólica en Obstetricia y Ginecología
}

\begin{abstract}
RESUMEN: Se realiza una revisión que comprende: los mecanismos de la hemostasia, los factores predisponentes de la enfermedad tromboembólica, los métodos diagnósticos, la profilaxis y el tratamiento de la misma.

Igualmente se hace hincapié en las heparinas de bajo peso molecular (HBPM) como drogas de elección en la tromboprofilaxis y el tratamiento durante el embarazo y en cirugía ginecológica.
\end{abstract}

PALABRAS CLAVES: Hemostasia, fibrina, trombina, plaquetas, plasmina, hipercoagulabilidad, trombosis, endotelial, estasis, heparina, warfarina, anticoagulante.

SUMMARY: This is a review that includes the following topics: the mechanisms of hemostasis, risk factors, diagnostic methods, prophylaxis and treatment of tromboembolic disease.

At the some time, special mention is made on the low mollecular weight heparins as the first line drug used for thromboprophylaxis and treatment during pregnancy and ginecologic surgery.

KEY WORDS: Hemostasis, fibrin, thrombin, platelet, plasmin, hypercoagulable, thrombosis, endothelial, stasis, heparins.

\section{Introducción}

El proceso de la hemostasia ha fascinado y creado confusión desde la antigüedad; desde entonces se han propuesto diversas teorías para explicar la transformación de la sangre líquida en un coágulo sólido.

En 1835, Buchanan (fisiólogo francés) comparó la coagulación de la sangre con la transformación de la leche al cuajarse y sugirió la existencia de un proceso enzimático que mediaba en ambos procesos (1).

En 1856, Rudolf Virchow resume su célebre tríada trombogénica: lesión endotelial, hipercoagulabilidad y estasis venosa, como factores que predisponen a la trombosis venosa (2).

El embarazo y la cirugía obstétrica representan dos circunstancias especiales para que se cumplan las condiciones de dicha tríada y se formen los trombos venosos. Es así como la incidencia de trombosis venosa profunda aumenta en unas cinco a siete veces en el postparto, comparada con el preparto; igualmente el riesgo de Enfermedad Tromboembólica (ETE) cuando el parto es atendido por cesárea, es tres a seis veces mayor, cuando se compara con la vía vaginal. Debemos recordar que un $15-24 \%$ de estas pacientes sin tratamiento desarrollan tromboembolismo pulmonar, con una mortalidad del 12 $15 \%(3)$.

En la paciente sometida a cirugía ginecológica, la tasa de trombosis venosa puede alcanzar el $17 \%$ o más dependiendo, entre otras variables, de la edad, el tipo de cirugía y diagnóstico previo (4).

Es por tanto importante que el gineco-obstetra conozca los mecanismos de la hemostasia, los factores predisponentes de la ETE, los métodos diagnósticos, la profilaxis y el tratamiento de la misma.

\section{Esquema de la coagulación}

La sangre se conserva líquida en el sistema circulatorio mediante un delicado equilibrio en el cual participan: el endotelio vascular, las plaquetas, los factores de coagulación y el sistema fibrinolítico. Este equilibrio puede romperse ante una injuria vascular, dando origen a la formación de un coágulo, el cual impide o disminuye la pérdida de sangre por el sitio de la lesión.

La hemostasia se lleva a cabo a través de tres etapas básicas que son:

- Hemostasia primaria o formación del tapón plaquetario.

- Hemostasia secundaria o formación del tapón de fibrina.

- Inhibidores de la coagulación y sistema fibrinolítico.

Hemostasia primaria o formación del tapón plaquetario: La injuria vascular estimula el proceso de la coagulación. La respuesta inicial del organismo es una vasoconstricción refleja, con la cual se reduce el flujo sanguíneo y el tamaño del coágulo para controlar la hemorragia (5).

Esta lesión vascular expone el tejido conectivo subendotelial (colágeno) y origina el depósito de plaquetas a nivel de lesión. La formación del tapón plaquetario depende de dos procesos interrelacionados que son: la adhesión y la agregación plaquetarias. Las plaquetas entonces, migran y cubren la superficie dañada, y liberan sustancias almacenadas en sus dos tipos de gránulos, así:

Gránulos densos: liberan ADP, potente agregante plaquetario, el cual estimula la síntesis de tromboxano $\left(\mathrm{TXA}_{2}\right)$ y serotina, los cuales mantienen la vasoconstricción refleja inicial. 
Gránulos alfa: liberan factor plaquetario, factor de crecimiento plaquetario, factor de permeabilidad vascular, factor de Von Willebrand (fundamental para el inicio de la adhesión plaquetaria), trombospondina y una proteína que neutraliza la heparina y estimula el crecimiento de fibroplastos y músculo liso vascular.

Estas sustancias atraen y fijan nuevas plaquetas, pero el restablecimiento de la presión intravascular puede desalojar el friable tapón plaquetario si no es reforzado por la formación de fuertes hebras de fibrina $(3,6-8)$.

En resumen el proceso de la hemostasia primaria es el siguiente (Figura 1).

\section{Hemostasia secundaria o formación del tapón de} fibrina:ésta consiste en un proceso enzimático secuencial en el cual se forma trombina, la cual permite la conversión del fibrinógeno en fibrina, la cual a su vez estabiliza el tapón plaquetario formando un coágulo insoluble.

Los factores que intervienen en este proceso son:

- Proteasas de serina: vitamina $\mathrm{K}$ dependientes: factores II, VII, IX, X

sistema de contacto: factores XI, XII y precalicreína Cofactores: plasmáticos: factores V, VIII, cininógeno APM y fibrinógeno

tisulares: factor tisular (III).

El proceso de la hemostasia secundaria consta de tres fases:

Fase I: activación del sistema intrínseco o generación de tromboplastina para activar el sistema extrínseco.

Fase II: formación de trombina a partir de protrombina y

Fase III: conversión del fibrinógeno en fibrina por acción de la trombina

\section{Figura 1}

\section{HEMOSTASIA PRIMARIA}



Figura 2

ESQUEMA DE COAGULACION FASES I Y II

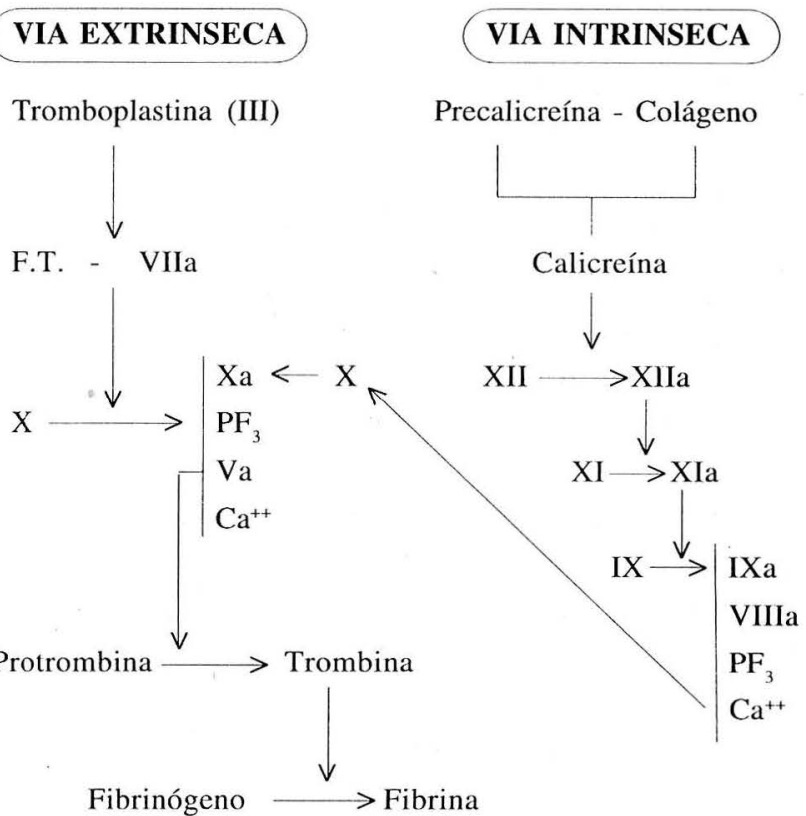

Fases I y II (ver figura 2): la trombina se forma a partir de dos vías diferentes: la vía intrínseca o intravascular que produce trombina a través de factores presentes solamente en el plasma y la vía extrínseca o tisular que utiliza factores extraplasmáticos (vía extrarrápida, en la cual se pasan por alto muchas reacciones del sistema intrínseco). El factor X se activa mediante cualquiera de las vías. La vía intrínseca (en la cual hay una activación secuencial de proteínas del plasma que se conoce con el nombre de "cascada de la coagulación") empieza con la activación del factor XII, el cual se activa por el contacto con el colágeno expuesto y por efecto de la calicreína. El factor XIIa activa el factor XI, el cual actúa sobre el IX y lo activa; una vez activado el factor IX y en presencia del factor VIII, $\mathrm{Ca}^{++} \mathrm{y}$ el factor tres plaquetario $\left(\mathrm{PF}_{3}\right)$, estimula el factor X para formar el factor Xa.

La vía extrínseca depende de un factor hístico llamado tromboplastina o factor III (el cual es un potente acelerador de la coagulación); ésta activa el factor VII, el cual junto con el factor tisular (F.T.), activa el factor X.

Después de la formación del factor Xa por alguna de las dos vías, las reacciones posteriores que llevan a la formación del coágulo de fibrina, son idénticas: un complejo formado por factor Xa, factor $\mathrm{V}, \mathrm{Ca}^{++} \mathrm{y}$ $\mathrm{PF}_{3}$ cataliza la conversión de protrombina en trombina (9-10).

1.2.3 Fase III: la trombina formada ataca la molécula de fibrinógeno, liberando los fibrinopéptidos $A$ y $B$, permitiendo la formación de monómeros de fibrina, que luego se polimerizan en fuertes uniones, reforzando al trombo (previamente débil) contra el aumento de la presión intravascular (ver figura 3). 
Figura 3

ESQUEMA DE COAGULACION - FASE III

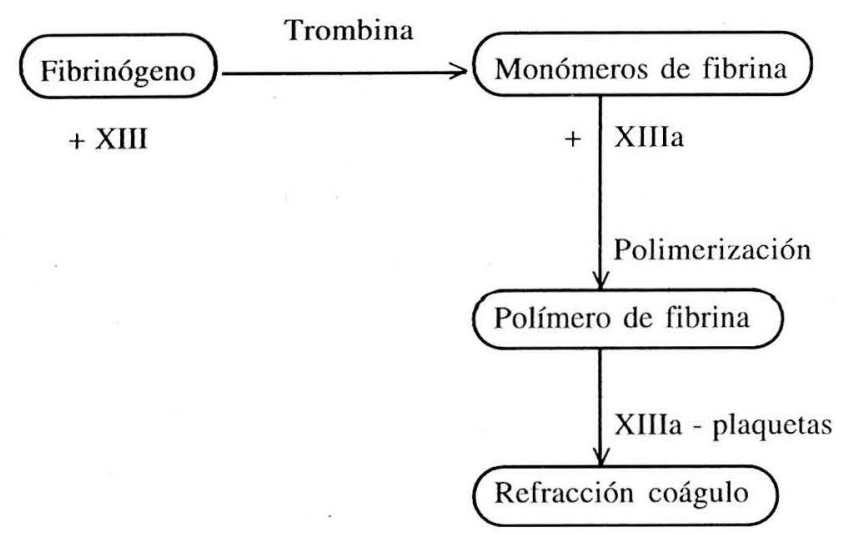

\section{Inhibidores de la coagulación y sistema fibrinolítico}

Inhibidores de la coagulación: existen varios mecanismos fisiológicos anticoagulantes que previenen la formación de trombos en casos normales o que limitan la formación del tapón hemostático al sitio de la lesión en estados patológicos. Ellos son:

- Prostaciclina $\left(\mathrm{PGI}_{2}\right)$ : sintetizada en las células endoteliales. Tiene efectos vasodilatadores y en presencia de AMP cíclico actúa como antiagregante plaquetario.

- Los tres mecanismos anticoagulantes mayores son:

Antitrombina III: proteína sintetizada por el hígado. Neutraliza trombina y factores IXa, Xa, XIa y XIIa. La acción de esta antitrombina III se potencia hasta 19 veces por las moléculas heparinoides presentes en la superficie endotelial (sobre todo a nivel de la microcirculación), las cuales son proteoglicanos conocidos como sulfatos de heparán (11).

Proteína C: vitamina $\mathrm{K}$ dependiente, producida en el hígado. Neutraliza factores VIIIa y Va.

Proteína S: vitamina K dependiente. Si el factor Va está unido a las plaquetas, la inactivación se logra sólo en presencia de proteína $S(8)$.

Sistema fibrinolítico: La activación de este sistema se inicia cuando la fibrina en contacto con el endotelio, libera activadores del plasminógeno (prourokinasa, urokinasa, activador tisular del plasminógeno o $\mathrm{t}$ - PA estreptokinasa) que promueven la conversión del plasminógeno en plasmina, enzima activa del sistema fibrinolítico (9) (ver figura 4).

La plasmina generada, digiere al complejo de fibrina, así como a las moléculas de fibrinógeno, dando lugar a los llamados productos de degradación de fibrinal fibrinógeno (PDF). Existen cuatro PDF: X - Y - D- E, los cuales son potentes anticoagulantes (figura 4). Ahora para evitar una diátesis hemorrágica, la plasmina es inactivada por varios mecanismos: la a2 antiplasmina, la a2 macroglobulina y la antitrombina III (llave de la figura 4) (8-9).

\section{Figura 4 \\ REPRESENTACION ESQUEMATICA DEL SISTEMA FIBRINOLITICO}

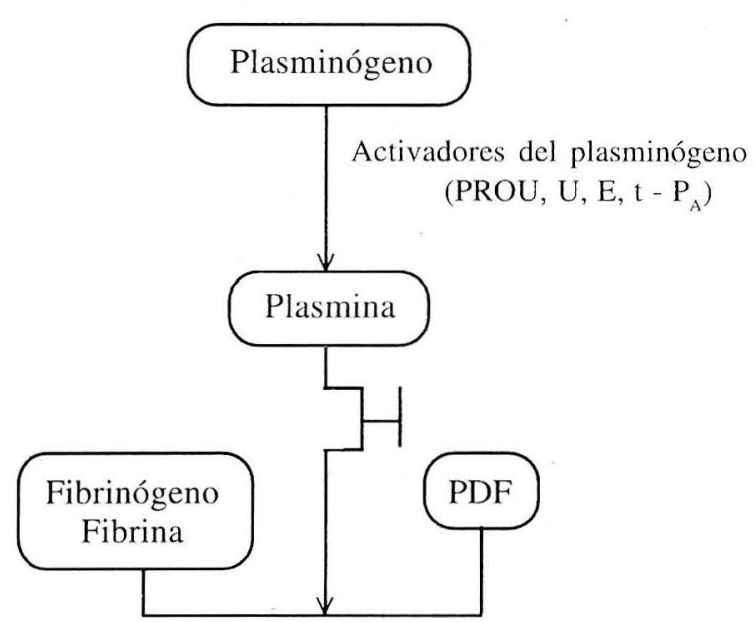

\section{Factores de riesgo para ETE} ETE:

En general existen dos estados que predisponen a la

Estados de hipercoagulabilidad primaria: desórdenes genético - familiares en los que la anormalidad específica es antagonizada por otros mecanismos fibrinolíticos normales (12). Comprenden: deficiencia de antitrombina III, deficiencia de proteína $\mathrm{C}$ y S, trastornos en el sistema fibrinolítico, disfibrinogenemia y deficiencia del factor XII.

Estados de hipercoagulabilidad secundaria: grupo de condiciones clínicas asociadas a alto riesgo de ETE. Son más frecuentes e importantes e incluyen:

Anormalidades de la coagulación y fibrinólisis: cáncer, anticonceptivos orales, síndrome nefrótico, anticoagulante lúpico y embarazo.

Anormalidades de vasos sanguíneos:

- Condiciones que promueven estasis venosa: inmovilización, reposo, cirugía mayor.

- Hiperviscosidad: policitemia vera, leucemias, anemia de células falciformes.

- Vasculitis y enfermedad oclusiva crónica: enfermedades autoinmunes, Takayasu, Buerger.

- Infección: Los trombos se producen por: lesión directa de la toxina bacteriana a la pared vascular con exposición del colágeno, hipotensión que lleva a estasis venosa e hipoxia asociada.

- Otras patologías: hemocistinuria, púrpura trombocitopénica trombótica, prótesis artificiales.

Anormalidades plaquetarias:

- Desórdenes mieloproliferativos: trombocitosis, hemoglobinuria paroxística nocturna.

- Diabetes Mellitus

- Otros factores: hiperbetalipoproteinemia tipo II, trombocitopenia por heparina.

Patogénesis de la ETE durante el embarazo: la tendencia a la ETE durante el embarazo (sobre todo a la trombosis venosa profunda) tiene su explicación. Cada 
elemento de la tríada de Virchow, se presenta en algún momento de la gestación, así: $(2,13)$.

\section{Estado de hipercoagulabilidad durante el embarazo y por lo menos seis semanas postparto, debido a:}

- Incremento de factores de coagulación: I, II, VII, IX, $\mathrm{X}, \mathrm{V}, \mathrm{VIII}, \mathrm{XII}$.

- Incremento en la adhesividad plaquetaria

- Incremento de la concentración de tromboplastina tisular en la placenta, la cual puede ser liberada en la circulación sistémica coincidiendo con el desprendimiento placentario, iniciando así la vía extrínseca de la coagulación.

- La placenta produce inhibidores de la fibrinólisis.

Contrarrestando parcialmente estos cambios precoagulantes, hay:

- Disminución en los factores XI (antecedente tromboplastínico del plasma) y XIII (factor estabilizador de la fibrina).

- Aumenta la síntesis de prostaciclina ( $\left.\mathrm{PGI}_{2}\right)$.

- Producción de PAPP - A: proteína específica del embarazo que facilita la neutralización de la trombina por la antitrombina III (como la heparina).

Sin embargo, el balance neto es: aumento en el potencial de trombosis, por aumento de los factores de coagulación y disminución de la fibrinólisis.

\section{Lesión endotelial:}

- Los niveles altos de estrógenos circulantes pueden causar degeneración en las fibras elásticas de la capa media de las venas y desgarro de la íntima subyacente.

- El endotelio vascular puede ser injuriado como resultado directo del trauma quirúrgico.

- La inoculación de bacterias en el sistema venoso durante la cirugía obstétrica puede causar injuria endotelial: las venas ováricas tienen comunicación extensa con los plexos venosos uterino y vaginal, facilitando así una puerta de entrada a las bacterias en la circulación venosa ovárica. La prevalencia de los trombos en la vena ovárica derecha, puede ser debida al drenaje retrógrado. de la vena ovárica izquierda y plexo venoso uterino en el plexo de la vena ovárica derecha. En presencia de endometriosis postparto, o postcesárea, este drenaje retrógrado puede hacer que la vena ovárica derecha reciba un alto inóculo bacteriano, resultando así la injuria endotelial y la formación de trombos.

- La lesión endotelial que ocurre en el momento del parto

En las cuatro situaciones anteriores, las plaquetas pueden adherirse a las áreas de desgarro endotelial y liberar factores que activan la vía intrínseca de la coagulación.

\section{Estasis del flujo venoso:}

- Al término del embarazo el diámetro de las venas ováricas es aproximadamente tres veces mayor, comparado con el estado no grávido y la capacidad de las venas aumenta 60 veces.

- La velocidad del flujo sanguíneo a través de las venas ováricas disminuye severamente después del parto.
- La disfunción de las hojillas de las valvas de las venas ováricas, especialmente la derecha, crean condiciones para la estásis (lagunas venosas que actúan como nidos de trombos).

- Dilatación de venas pélvicas y de miembros inferiores por la comprensión del útero y por los cambios hormonales (progesterona) que llevan a la relajación del músculo liso. La vena ovárica derecha está sujeta a comprensión por el útero y el uréter dilatado.

- Aumento del volumen sanguíneo y de la viscosidad del plasma, lo que sumado a lo anterior, favorece la estasis.

\section{Frecuencia de la ETE}

$\mathrm{La}$ incidencia de tromboflebitis de los miembros inferiores en el anteparto es de más o menos $2 \times$ cada 1.000 embarazos (casi la misma que en las no embarazadas). De éstas, la mayoría son superficiales $(1,7 \mathrm{x}$ cada 1.000 embarazos); las trombosis venosas profundas son raras (3,6 x cada 10.000 embarazos).

$\mathrm{La}$ incidencia de tromboflebitis superficial aumenta unas siete veces ( $12 \mathrm{x}$ cada 1.000 embarazos) y las trombosis venosas profundas lo hace cinco veces $(15 \mathrm{x}$ cada 10.000 embarazos) durante el período postparto. Resulta paradójico que el postparto sea el momento con mayor riesgo de complicaciones tromboembólicas, ya que en este período se produce un rápido aumento de la actividad fibrinolítica del plasma y de toda la sangre.

Por su parte el tromboembolismo pulmonar se observa rara vez durante la gestación, presentándose con una incidencia del 2,7 x 1.000; en alrededor del 95\% de los casos el tromboembolismo pulmonar se produce como resultado de una trombosis venosa profunda íleofemoral, por lo general en el postparto inmediato (14).

La trombosis venosa pélvica (TVP) se presenta entre el 5 y $10 \times 1.000$ de todos los partos.

\section{Diagnóstico clínico de la ETE}

La ETE incluye tromboflebitis profunda (TFP), trombosis venosa pélvica (TVP) y embolismo pulmonar (EP).

Los síntomas y signos de la ETE dependen de la obstrucción del retorno venoso, sola o acompañada de inflamación vascular. La mayoría de los trombos demostrados por métodos diagnósticos son asintomáticos, incluso en presencia de embolismo pulmonar, el $80 \%$ sufren lisis espontánea.

Los síntomas y signos de la ETE son inespecíficos y las entidades que pueden confundirla son: rotura de un quiste de Baker, hematomas musculares, miositosis, neuritis, artritis, linfangitis y síndrome varicoso.

Los principales síntomas y signos de la ETE dependen de la localización del trombo, así:

Tromboflebitis superficial: afecta las venas safenas y es más frecuente que la TFP. Las venas afectadas se palpan sensibles, calientes y eritematosas. Rara vez embolizan.

Tromboflebitis profunda: son difíciles de diagnosticar, ya que el dolor y la hipersensibilidad del embarazo pueden simular su presencia. Ocurre generalmente en las venas de los miembros inferiores; en el $80 \%$ de las 
gestantes la trombosis se inicia en las venas ilíacas y femorales. Se manifiesta por:

- Dolor o sensibilidad en las pantorrillas

$60-90 \%$

- Aumento de la temperatura y

edema unilateral

$40-75 \%$

(dos o más centímetros en el diámetro

de la extremidad afectada)

- Signo de Homans (dolor

hiperextensión pie)

- Prueba de Lowenberg

(incremento del dolor distal al

inflar tensiómetro a $180 \mathrm{~mm} \mathrm{Hg}$ )

- Varicosidades superficiales

- Cambios de coloración de la extremidad

(se dan en casos severos con compromiso

del flujo arterial,

originando la Flegmasia Cerúlea Dolens.

Aquí hay: cianosis,

disminución pulsos y extremidad fría).

- El comienzo es repentino y casi siempre se produce en el puerperio.

- Se asocia con: parto por cesárea, obesidad, edad materna avanzada, multiparidad, toma de estrógenos para suprimir la lactancia, varicosidades, complicaciones obstétricas que requieren reposo prolongado en cama y con deficiencia de la actividad de los anticoagulantes naturales (antitrombina III y proteínas $\mathrm{C}$ y $\mathrm{S}$ ).

- Las principales complicaciones son el síndrome prostrombótico y el embolismo pulmonar. Este último se presenta hasta en el 50\% de los casos (14-16).

Embolismo pulmonar: constituye la complicación más grave de la trombosis venosa y la tercera causa de muerte de origen cardiovascular. Si bien el EP puede manifestarse en cinco formas diferentes, en el tromboembolismo pulmonar clásico, el espectro clínico corresponde a una enfermedad cardiopulmonar aguda, encontrándose signos de rápida dilatación del ventrículo derecho, acentuación y desdoblamiento del segundo ruido pulmonar $(50 \%)$. Además: disnea (70\%), taquipnea, broncoespasmo, tos seca, hemoptisis, dolor torácico (65\%) y lipotimia (4\%). La taquipnea mayor de 16 por minuto es un hallazgo frecuente (80-90\%), crépitos basales (50\%), taquicardia (45\%), fiebre $(50 \%)$, presencia de S3 ó S4 $(34 \%)$, arritmias $(7 \%)$.

Las enfermedades cardíacas preexistentes predisponen al infarto pulmonar, cuyos signos clásicos son: dolor pleurítico agudo, disnea y hemoptisis (15).

Trombosis venosa pélvica: la TVP se presenta entre el 0,5-1\% de todos los partos. Es una complicación de la infección puerperal que pone en peligro la vida de la paciente. Puede causar enfermedad multisistémica como también enfermedad localizada en la pelvis. En el 32$38 \%$ de los casos puede originar embolismo pulmonar recurrente.

La TVP se puede presentar como dos síndromes clínicos diferentes:

1. Trombosis aguda de la (s) vena (s) ovárica (s) (TAVO) y

2. Trombosis difusa de múltiples pequeños vasos pélvicos.
El desorden más comúnmente descrito es el de la TAVO. Por ser éste más frecuente en el lado derecho, muchos autores lo conocen como "el síndrome de la vena ovárica derecha". La TAVO ha sido reportada clásicamente por Brown y Munsick. Inicialmente la paciente presenta cuadro compatible con endomiometritis o celulitis pélvica, para lo cual recibe tratamiento médico, sin ninguna mejoría. El signo más importante es la detección de una masa que corresponde a la vena trombosada, la cual se origina centralmente cerca al cuerno uterino y se extiende lateral y cefálicamente hacia el abdomen superior.

El segundo desorden ha sido descrito como "fiebre enigmática", ya que no hay un origen claro para el aumento recurrente de la temperatura. Este síndrome es descrito adecuadamente por Gibbs, Dun, Vorrhis y Schulman. Estas pacientes también tienen evidencia de infección y reciben tratamiento, mejorando definitivamente, con excepción de la inestabilidad térmica. La paciente no aparece críticamente enferma $(2,13)$.

Las características especiales de cada síndrome, se resumen en el cuadro 1.

\section{Ayudas diagnósticas de la ETE}

Tromboflebitis profunda (TFP): las pruebas diagnósticas son invasoras y no invasoras. Las primeras son más sensibles y específicas, pero implican más riesgo para la paciente. Las no invasoras son fiables, pero su precisión está afectada por las alteraciones fisiológicas del embarazo. Una prueba no invasora positiva durante la gestación, debe confirmarse con venografía después de la semana 20 . En resumen:

La venografía: es el mejor método para establecer el diagnóstico de TFP, pero no es un procedimiento inocuo ya que es invasivo. Es el método más seguro para diagnosticar las trombosis en las pantorrillas, pero con una técnica adecuada se puede valorar toda la extremidad inferior, incluyendo las venas ilíacas externa y primitiva. No es útil para valorar vasos pélvicos. Es positiva cuando hay un bloqueo venoso $(2,15)$. Dada la ocurrencia de falsos positivos para TFP en la mujer embarazada y los riesgos de la anticoagulación, se considera a la venografía como una prueba indispensable para iniciar el tratamiento.

Pletismografía de impedancia: es un instrumento capaz de registrar variaciones en el volumen de una extremidad. En nuestro medio se utiliza la neumática, con una sensibilidad y especificidad del 90 al $95 \%$ cuando la obstrucción venosa está en el segmento íliofemoropoplíteo. No tiene utilidad para diagnosticar TFP de la pantorrilla. No distingue la oclusión trombótica de la no trombótica, por lo que la oclusión de la vena cava inferior por el útero grávido puede dar falsos positivos.

Ultrasonido doppler: últimamente se emplea cada vez más la combinación de ecografía en tiempo real y ecografía doppler (doppler-duplex) para el diagnóstico de TFP. El doppler-duplex tiene una sensibilidad del 92-95\% y una especificidad del $97-100 \%$, las cuales se incrementan con la adición del color (triplex), ya que facilita la visualización de trombos en las ramas de la poplítea. Para algunos en buenas manos es el método de elección (14-16). 
Cuadro 1

COMPARACION DE LA TAVO Y SINDROME DE FIEBRE ENIGMATICA

\begin{tabular}{|c|c|c|}
\hline Parámetro & TAVO & S.F. Enigmática \\
\hline Fisiopatología & $\begin{array}{l}\text { Asociado o no con infección del sitio } \\
\text { operatorio. }\end{array}$ & Casi siempre asociado a infección del sitio operatorio. \\
\hline Iniciación & 2-4 días post-operatorio & 4-8 días post-operatorio. \\
\hline Evolución clínica & Ataque agudo & Evolución lenta \\
\hline Apariencia de la paciente. & Agudamente enferma & Buena, excepto durante el aumento de la temperatura. \\
\hline Frecuencia cardíaca & Aumentada & Aumentada durante el ascenso de la temperatura. \\
\hline Sensibilidad y dolor & Abdominopélvicos moderados a severos. & Usualmente ausentes. \\
\hline Masa & $50-67 \%$ en uno o ambos cuadrantes. & Usualmente ausente \\
\hline Motilidad intestinal & Ileus adinámico o normal & Usualmente normal \\
\hline Embolización pulmonar. & $\begin{array}{l}\text { Scan V/Q anormal en una tercera parte de } \\
\text { pacientes. }\end{array}$ & Scan V/Q anormal en una tercera parte de pacientes. \\
\hline Intervención quirúrgica. & $\begin{array}{l}\text { Indicación frecuente para excluir otras enfer- } \\
\text { medades. }\end{array}$ & Menos frecuente para excluirlas. \\
\hline Confirmación diagnóstica. & $\begin{array}{l}\text { Establecida por LE. } \\
\text { Venografía. } \\
\text { TAC versus IRM anormal. }\end{array}$ & $\begin{array}{l}\text { Diagnóstico exclusión. } \\
\text { Confïmada por respuesta al tratamiento con heparina. } \\
\text { Venografía. } \\
\text { TAC versus IRM menos probablemente anormal. }\end{array}$ \\
\hline Diagnóstico diferencial & $\begin{array}{l}\text { Apendicitis aguda, hematoma o flemón liga- } \\
\text { mento ancho, torsión anexo, ureterolitiasis, } \\
\text { pielonefritis, absceso, mioma degenerado. }\end{array}$ & $\begin{array}{l}\text { Fiebre por drogas, enfermedades vasculares del } \\
\text { colágeno, síndrome viral, absceso. }\end{array}$ \\
\hline
\end{tabular}

Gamagrafía con fibrinógeno marcado con $\mathrm{I}(1,25)$ : el fibrinógeno cuando se inyecta en la corriente sanguínea, es captado e incorporado al trombo en formación. Es una técnica excelente para diagnosticar TFP en la pantorrilla y en tercio inferior del muslo, pero está contraindicada en la mujer embarazada y en la que va a lactar, ya que pasa al feto a través de la placenta y la leche y se concentra en el tiroides fetal (su efecto dura hasta 60 días) $(2,14-15)$.

Embolismo pulmonar: además del examen físico, los rayos x de tórax, el EKG y los gases arteriales ayudan al diagnóstico posible. Sin embargo, los métodos más confiables para el diagnóstico de EP son la gamagrafía de ventilación - perfusión (V/Q) y la arteriografía pulmonar.

Rayos x de tórax: se han descrito siete signos más o menos típicos: amputación de una arteria pulmonar, pulmón isquémico, imagen pulmonar de infarto, elevación de un hemidiafragma, dilatación de una arteria pulmonar o del ventrículo derecho, atelectasia y derrame pleural (15).
E.K.G.: es normal en el $30 \%$ de las pacientes y en el $75 \%$ los hallazgos no son específicos, incluyendo: arritmias (taquicardias supraventriculares, fibrilación auricular, contracciones ventriculares prematuras), sobrecarga cardíaca derecha (patrón $\mathrm{S}_{1} \mathrm{O}_{3} \mathrm{~T}_{3}$ - bloqueo de rama derecha y desviación del eje a la derecha), inversión de la onda $\mathrm{T}$ y ondas P altas en II, III y AVF.

Gases arteriales: un hallazgo muy frecuente es la presencia de alcalosis respiratoria con hipoxemia e hipocapnia $\left(\mathrm{PO}_{2}\right.$ inferior a $80 \mathrm{~mm} \mathrm{Hg}$ y $\mathrm{PCO}_{2}$ superior a $30 \mathrm{~mm} \mathrm{Hg}$ ). Son normales en el 6\% (15-16).

Gamagrafía de V/Q: es el método diagnóstico no invasivo de elección en la paciente con sospecha clínica de E.P... Inicialmente se realiza la gamagrafía de perfusión (Q), la cual se interpreta como positiva cuando se registran zonas que no captan el radio trazador (macroagregados de albúmina marcados con Tc 99). Es útil cuando los rayos $x$ de tórax son normales. Puede dar falsos positivos en presencia de quistes, bulas enfisematosas, tumores, atelectasias, neumonías, EPOC y sarcoidosis. 
La gamagrafía de ventilación (V) sirve como complemento de la gamagrafía de perfusión, mejorando la especificidad (para descartar los falsos positivos); aquí se emplea un isótopo de xenón inhalado inmediatamente antes o después del estudio de Q.

En general se reportan tres patrones gamagráficos: alta probabilidad, intermedia y baja. Un estudio de baja probabilidad descarta E.P., uno de alta probabilidad tiene una sensibilidad del $82 \%$ y una especificidad cercana al $90 \%(15-16)$.

Arteriografía (angiografía): es considerada como la técnica más específica para diagnosticar E.P. Está indicada en las pacientes con alta sospecha clínica y en quienes por otros métodos como el gamagráfico no haya podido llegarse a una conclusión diagnóstica (15-16). Esta técnica invasiva implica los riesgos del cateterismo y reacciones al medio de contraste.

Trombosis venosa pélvica (TVP): hasta hace poco, el diagnóstico de la TVP se hacía intraoperatoriamente en pacientes con masa pélvica, síndrome febril y dolor en FID o tras la respuesta satisfactoria a la prueba terapéutica con heparina. Además, se han utilizado métodos como: la urografía, la venografía femoral, la flebografía uterina y el ultrasonido para aproximarse al diagnóstico.

Actualmente, gracias al progreso de la imagenología, han cogido gran auge: la tomografía axial computarizada (TAC) y la imagen de resonancia magnética (IRM) (15-16).

TAC: recurso adecuado no sólo para realizar el diagnóstico, sino también en el seguimiento de la trombosis venosa profunda proximal y pélvica. El método se lleva a cabo usando medio de contraste. Los criterios usados para el diagnóstico de trombosis venosa por TAC, son los recomendados por Zerhouni y colaboradores. Estos son:

- Ensanchamiento de la vena

- Una baja densidad de flujo luminoso dentro de la pared del vaso y

- Una pared del vaso agudamente definida, mejorada por el medio de contraste.

IRM: lo que más ha revolucionado el diagnóstico de TVP es la IRM, técnica bastante costosa (vale el doble del TAC). Tiene la ventaja de que en ella no se usan en medios de contraste y de que los vasos normales aparecen oscuros debido a la presencia de flujo sanguíneo, mientras que los trombos se ven claros (color blanco leche).

Eco doppler: puede ayudar, pero aún necesita perfeccionarse para que sea bien confiable.

\section{Profilaxis de la ETE en obstetricia}

Como se mencionó antes, la paciente obstétrica presenta a menudo uno o más factores de riesgo para desarrollar ETE (riesgo cinco veces mayor comparado con la no gestante); por tanto es necesario tomar las medidas pertinentes, tendientes a minimizar la aparición de la enfermedad.

La profilaxis de la tromboembolia está indicada en tres situaciones durante el embarazo: (17)

- Gran peligro de ETE sin antecedentes

- Antecedentes de ETE agudos o lejanos (TFP íliofemoral - TVP - EP)

- Deficiencia de antitrombina III, proteínas C y S
Posibles indicaciones obstétricas de profilaxis de ETE son:

- Antecedentes de ETE (antes o durante el embarazo)

- Pacientes con prótesis valvulares cardíacas mecánicas

- Estenosis mitral versus fibrilación auricular

- Miocardiopatía periparto

- Parto operatorio (cesárea o fórceps medio)

- Preeclampsia - eclampsia

- Anemia

- Infecciones

- Varicosidades extensas versus obesidad versus reposo

- Terapia con estrógenos para suprimir la lactancia

- Uso de anticonceptivos orales antes de la concepción

- Enfermedad maligna simultánea

A continuación se describen los métodos profilácticos de elección en el embarazo, su mecanismo de acción y esquemas de uso.

Heparina: es un poderoso anticoagulante que pertenece al grupo de los polielectrolitos aniónicos; es un mucopolisacárido denominado glucosaminoglicano sulfatado, con grupos carboxílicos que le dan un carácter ácido. La heparina para uso terapéutico se extrae de la mucosa intestinal porcina o del pulmón bovino. Por su peso molecular se distinguen:

- Heparina estándar (60.000-100.000 daltons) daltons

- Heparinas de bajo peso molecular (HBPM) - $<7.000$

- Heparitinas y condroitines polisulfatados

Mecanismo de acción: la heparina produce su efecto anticoagulante por la formación de un complejo con la antitrombina III (cofactor de la heparina), el cual neutraliza o inhibe los factores de coagulación activados en la vía intrínseca y común de la coagulación, incluyendo trombina (IIa), Xa, IXa, XIa, XIIa y calicreína (siendo cuantitativamente más importantes la inhibición de la trombina y del factor Xa). El complejo heparina antitrombina III producen una neutralización $1.000 \mathrm{ve}-$ ces más rápida sobre la trombina y el factor Xa que la antitrombina sola (ver figuras 5 y 6 ).

- Por tanto, impide la conversión de fibrinógeno en fibrina

- Disminuye la adhesividad plaquetaria

- Bloquea la permeabilidad capilar causada por prostaglandinas, histamina y bradikininas

- Inhibe competitivamente a la adenosin-trifosfatasa, disminuyendo la construcción de células endoteliales.

- Reduce rigidez de las capas superficiales del fibrinógeno $(8-9,10,18)$.

\section{Presentación:}

- Liquemine: frasco ampolla de 5 cc con 25.000 UI para uso IV o SC uso IV

- Fepaheparina: ampolla de 5 cc con 25.000 UI para

- Heparina sódica: frasco ampolla de $10 \mathrm{cc}$ con 5.000 $\mathrm{UI} / \mathrm{cc}$.

Vías de administración: intravenosa o subcutánea. Es ineficaz por vía oral.

Eliminación: por hígado y riñón. Su aclaramiento plasmático se produce aún en caso de enfermedad de estos órganos, por fijación al endotelio vascular, retención en macrófagos y sistema reticuloendotelial. 


\section{Complicaciones:}

La complicación más importante es la hemorragia (5-20\%), la cual es siete veces más frecuente cuando se administra en bolos comparada con la infusión IV continua.

- Hematomas: si se aplica por vía IM.

- Profilaxis con dosis bajas: aumenta ligeramente el riesgo de hematomas a nivel de las heridas.

- Profilaxis con dosis altas: aumenta el riesgo de hematomas a nivel de las heridas y de la episiotomía; además puede contribuir al aumento del sangrado en caso de atonía o retención placentaria.

- Dosis mayores a 15.000 UI/día durante seis o más meses, pueden producir osteoporosis (inhibición por la heparina de la 1a hidroxilación de la 25 hidroxivitamina $\mathrm{D}$ en el riñón).

- Trombocitopenia en el 20\% de las pacientes (más con la heparina del pulmón bovino). Además, el 1-2\% de las pacientes que reciben heparina, desarrolla trombocitopenia severa de mediación inmune, la cual aparece en los primeros 7-10 días de tratamiento y es debida al desarrollo de anticuerpos contra el complejo heparina-plaquetas.

- Menos frecuentes son: la necrosis grasa, la alopecia y reacciones de hipersensibilidad.

Antídoto: sulfato de protamina a la dosis de $1 \mathrm{mg}$ por c/100 unidades de heparina. Dado que la vida media de la heparina es de 90 minutos, se da únicamente la mitad de la dosis de protamina calculada. No se deben administrar más de $50 \mathrm{mg}$ en 10 minutos, ni más de $100 \mathrm{mg}$ como dosis total, ya que el exceso produce hemorragia.

Precaución: usar con cuidado medicamentos que inhiben la agregación plaquetaria (ASA, Dextranos y Dipiridamol), ya que puede aumentar el riego de hemorragia (9).

Exámenes básicos: hematocrito-hemoglobina, plaquetas cada tres días, TPTA.

Esquemas profilácticos: a las pacientes en peligro de ETE, las beneficia un aumento de la actividad de la antitrombina III. Dosis bajas de heparina (5.000 UI cada 12 horas por vía SC) son eficaces y seguras para prevenir la ETE en la paciente obstétrica y en la ginecológica postoperatoria con enfermedad benigna o maligna.

Ahora, durante el embarazo la dosis de heparina necesaria es mayor, debido: al aumento del volumen plasmático, al mayor aclaramiento renal, a la presencia de heparinasa placentaria y al aumento de lípidos de baja densidad durante el parto. Las dosis recomendadas, por tanto, son:

$<12$ semanas 5.000 UI cada 12 horas por vía SC

13-29 semanas 7.500 UI cada 12 horas por vía SC

330 semanas 10.000 UI cada 12 horas por vía SC

\section{Los esquemas son:}

- Profilaxis perioperatoria: la droga se debe iniciar dos horas antes del procedimiento y se debe prolongar durante dos o tres días, hasta que la paciente deambule normalmente $(8,17,19)$.

- Válvulas mecánicas cardíacas: todas las pacientes embarazadas en quienes se inserten válvulas cardíacas mecánicas, deben estar continuamente anticoaguladas.
La heparina se administra durante todo el embarazo, parto y puerperio inmediato.

- Antecedentes de ETE (TFP-TVP-EP): se dará heparina profiláctica durante todo el embarazo, parto y puerperio, hasta que desaparezcan los factores de riesgo. Luego del parto, la heparina se disminuye a 5.000 UI cada 12 horas por vía $\mathrm{SC}$.

- ETE durante el embarazo: se hará tratamiento anticoagulante durante 10 a 14 días y luego se continúa con heparina subcutánea a las dosis indicadas, durante el resto del embarazo, parto y puerperio, continuando con coumadín hasta completar tres a seis meses (según se trate de una TFP, una TVP o de un Ep. Se exceptúa la trombosis difusa de los múltiples pequeños vasos pélvicos, la cual se trata durante 10 a 14 días).

Un episodio trombótico durante los primeros tres a seis meses de gestación, obliga a una profilaxis adecuada, ya que sin ella el peligro de recidiva agudo es alto $(30 \%)$.

Idealmente el esquema de heparina profiláctico debe ajustarse a buscar un TPTA de 1,2 a 1,5 veces el normal, pero tal ajuste no es necesario.

Heparinas de bajo peso molecular (HBPM): la heparina estándar (HE) o no fraccionada puede ser despolimerizada por métodos químicos o enzimáticos, obteniéndose productos de bajo peso molecular $(<7.000$ daltons) conocidos con el nombre de HBPM . Los distintos tipos de producción de HBPM dan lugar a preparados con diferentes efectos antitrombóticos, de modo que dichos preparados deben considerarse disímiles, tanto en su dosificación como en su aspecto biológico; por tanto las dosis aconsejadas no son extrapolables de un producto a otro $(8-10,18-19)$. Comercialmente existen: enoxaparina sódica (clexane, lovenox, klexane), nadroparina cálcica (fraxiparina), dalteparina sódica (fragmín), reviparina sódica (clivarine), tinzaparina sódica (logiparina), RD heparina (normiflo) y HBPM Sandoz (mono-embolex). Se usan y se consiguen en nuestro medio:

- Enoxaparina sódica (clexane): jeringas prellenadas con $20 \mathrm{mg} / 0,2 \mathrm{ml}, 40 \mathrm{mg} / 0,4 \mathrm{ml}, 60 \mathrm{mg} / 0,6 \mathrm{ml}$ y $80 \mathrm{mg} /$ $0,8 \mathrm{ml}(1 \mathrm{mg}=100 \mathrm{UI}$ anti-Xa) para uso $\mathrm{SC}$ en caja por 2 jeringas.

- Nadroparina cálcica (fraxiparina): jeringa prellenada con 7.500 UIC (Unidades Instituto Choay) en $0,3 \mathrm{ml}$, que equivalen a $3.075 \mathrm{UI}$ anti-Xa, en caja por 2 jeringas para uso SC.

- Dalteparina sódica (fragmín): jeringa desechable con 2.500 UI (2.500 UI anti-Xa) o 5.000 UI (5.000 UI anti-Xa) en $0,2 \mathrm{ml}$ en dosis única y ampollas de 10.000 $\mathrm{UI} / 1 \mathrm{ml}$, en dosis única para uso $\mathrm{SC}$.

Mecanismo de acción: el sitio de unión de la AT-III en la heparina es una secuencia específica de un pentasacárido que contiene un residuo de glucosamina 30 sulfatada (estructura observada en el $30 \%$ de las moléculas de heparina). Este pentasacárido cataliza la inhibición del factor Xa por la AT-III; la catálisis se produce sólo por inducción de un cambio conformacional en la AT-III que facilita la reacción con la proteasa (ver figura 5). Ahora, las moléculas de heparina que contienen menos de 18 unidades de monosacáridos no catalizan 
la inhibición de la trombina (factor IIa) por la AT-III; de ahí que se requieran moléculas de esta longitud o mayores para fijar trombina y AT-III en forma simultánea (ver figura 6).

Por su parte, las HBPM se unen a la AT-III y producen un efecto anti-Xa altamente selectivo, ya que poseen la secuencia pentasacárida requerida para el efecto antitrombótico de la heparina. Esta actividad anti-Xa es inversamente proporcional el peso molecular del fragmento de heparina (ver figura 5).

Por otro lado, la actividad de las HBPM contra el factor IIa es menor (3,5 a 5 veces menos que la heparina) ya que no poseen la longitud suficiente de unidades de monosacáridos para catalizar la inhibición de la trombina (ver figura 6) (10, 21-23).

Eliminación y antídoto: las HBPM se eliminan principalmente por el riñón y su antídoto es también la protamina.

Ventajas de las HBPM:

- Gran actividad antifactor Xa y débil acción frente a la trombina (IIa). Lo anterior se traduce en un gran efecto antitrombótico y un débil efecto anticoagulante.

- Menos riesgo de hemorragia (menos efecto sobre factor IIa)

- Menor incidencia de trombocitopenia (menor efecto sobre factor IV plaquetario).

- Mejor biodisponibilidad

- Prolongada vida media

Lo que permite terapia $\mathrm{SC}$ en 1-2 dosis/día

Figura 5

MECANISMO DE ACCION-INACTIVACION DEL FACTOR Xa

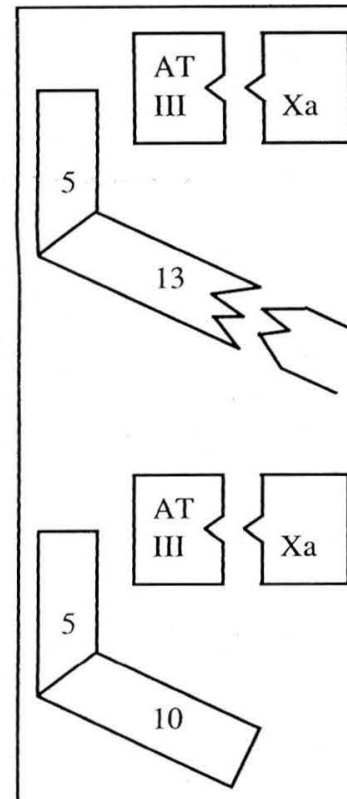

LIGA ATIII

\section{HEPARINA}

\section{HBPM}

\section{Explicación:}

Para inactivar el factor $\mathrm{Xa}$, la heparina debe ligar ATIII a través de la alta afinidad pentasacárida, pero no necesita ligar al factor Xa. Por tanto, la HE y las HBPM son capaces de inactivar el factor $\mathrm{Xa}$.
Figura 6

MECANISMO DE ACCION-INACTIVACION DEL FACTOR IIa (TROMBINA)

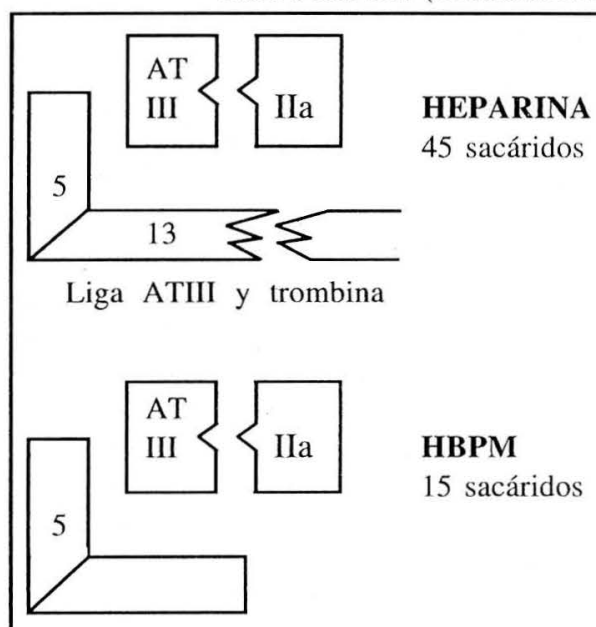

\section{LIGA ATIII, PERO NO TROMBINA}

\section{Explicación:}

Para inactivar la trombina, la heparina debe ligar ATIII a través de la alta afinidad pentasacárida y trombina a través de una unidad adicional de 13 sacáridos. Las HBPM que contienen menos de 18 sacáridos, no pueden ligar la trombina y por tanto, son incapaces de inactivar la trombina.

- Menor incidencia de osteoporosis

- Prácticamente no requieren controles biológicos

- Son más efectivas que la HE en la prevención del tromboembolismo recurrente

- Amplio uso en la profilaxis tromboembólica en cirugía general y ortopédica

- Se asocian con una baja rata de mortalidad, principalmente en el subgrupo de pacientes con cáncer.

- La administración ambulatoria (hogar) disminuye los costos de la hospitalización

- Fácil aplicación, lo que mejora tolerancia y obediencia $(9,23-26)$.

Experiencia en obstetricia y ginecología: si bien las HBPM se introducen en Europa para uso clínico hace más de 10 años, la experiencia obstétrica es limitada y la mayoría de las series reportadas no tienen grupo control. La serie más larga con grupo control es reportada por Omri y colaboradores, quienes usan HBPM en 17 pacientes para profilaxis tromboembólica, con 10 pacientes no tratadas como controles (23). Por otro lado, la práctica con estas HBPM para la profilaxis tromboembólica en cirugía ginecológica es extensa y con grupos de control adecuados.

La revisión de la experiencia publicada con relación al uso de las HBPM en obstetricia y ginecología revela que:

- Son eficaces, seguras y para muchos las drogas de elección, en la tromboprofilaxis y tratamiento durante el embarazo, trabajo de parto, parto y puerperio.

- Son ideales en la tromboprofilaxis y tratamiento en la cirugía ginecológica. 
No atraviesan la barrera placentaria en ningún trimestre

- No producen efectos teratogénicos ni mutagénicos

Las principales indicaciones para su uso fueron: antecedente de ETE en gestaciones previas, episodio tromboembólico agudo durante el embarazo, síndrome antifosfolípido, lupus eritematoso sistémico con o sin anticuerpos antifosfolípidos y profilaxis tromboembólica y tratamiento en cirugía ginecológica $(9,23,25,27-34)$.

\section{Esquemas y dosis:}

- Profilaxis perioperatoria: en cirugías con riesgo trombogénico moderado: aplicar una ampolla de clexane $(20 \mathrm{mg}=2.000 \mathrm{UI}$ anti-Xa) o de fraxiparina (3.075 UI anti-Xa) o de fragmín (2.500 UI anti-Xa) por vía SC, 24 horas antes de la intervención. Luego se continúa con una ampolla diaria.

- En cirugías con riesgo trombogénico alto aplicar:

Clexane: una ampolla de $40 \mathrm{mg}$ (4.000 UI anti-Xa) 12 horas antes de la intervención. Luego una diaria, O

Fraxiparina: una ampolla de 7.500 UIC $(3.075 \mathrm{Ui}$ anti-Xa) 12 horas antes y 12 horas después de la intervención. Luego se aplica una ampolla/día hasta el tercer día. A partir del cuarto día se aplican 10.000 UIC $(0,4 \mathrm{ml}) \mathrm{si}$ el peso es $£ 70 \mathrm{~kg}$ ó 15.000 UIC $(0,6 \mathrm{ml})$ si el peso es > de $70 \mathrm{~kg}$ por vía $\mathrm{SC}, \mathrm{O}$

Fragmín: una ampolla de 2.500 UI anti-Xa, 2-4 horas antes de la intervención y 12 horas postcirugía. Los días siguientes se administrarán 5.000 UI anti-Xa/día ó 2.500 UI anti-Xa 2 veces/día.

El tratamiento debe seguirse durante todo el período de riesgo o hasta la completa movilización de la paciente.

- Antecedentes de ETE: igual manejo, dependiendo del riesgo

- ETE durante el embarazo o postcirugía ginecológica: la droga más usada es la enoxaparina (clexane), administrada a razón de $60-80 \mathrm{mg}$ cada 12 horas por vía SC durante 10 días. La dosis por inyección es de $1 \mathrm{mg} / \mathrm{kg}$ $=100 \mathrm{UI} / \mathrm{kg}(1 \mathrm{mg}=0,01 \mathrm{ml}=100 \mathrm{UI}$ anti-Xa $)$. Luego se continúa con dosis profilácticas, generalmente $40 \mathrm{mg} /$ día, en una sola inyección, durante el resto del embarazo, parto y puerperio (administración por períodos de seis semanas a seis meses).

\section{Control biológico:}

- Control de plaquetas durante la heparinoterapia

- Medición de la actividad anti-Xa (preferiblemente por el método amidolítico): la toma de la muestra se hace el segundo día del tratamiento, entre la tercera y cuarta hora postinyección. El rango terapéutico se sitúa entre 0,5 y 1 UI anti-Xa/ml.

Warfarina: es un derivado de la $4 \mathrm{OH}$ cumarina, utilizada en forma de sal sódica en la profilaxis y tratamiento de la ETE. Esta pequeña molécula se une en el 97\% a las proteínas plasmáticas (albúmina) y el 3\% restante ejerce su efecto en el hígado, donde es metabolizada a restos inactivos que son eliminados por orina y heces. Cruza fácilmente la placenta y se excreta por la leche materna (34).

Mecanismo de acción: actúa impidiendo que la vitamina $\mathrm{K}$ intervenga en el hígado en la gamacarboxilación de los residuos terminales de ácido glutámico de la protrombina, de los factores VII, IX y X y de las proteínas
C y S. Los cumarínicos bloquean la acción de una reductasa que transforma la vitamina $\mathrm{K} 1$ epóxido (inactivo) en una forma hidroquinona (activa) en los microsomas hepáticos. El inicio del efecto depende de la vida media de los factores: los primeros en ser inhibidos son la proteína $\mathrm{C}$ y el factor VII, completándose la inhibición de los otros factores 48 a 72 horas más tarde. En resumen, los cumarínicos afectan la síntesis de los factores de coagulación vitamina $\mathrm{K}$ dependientes $(8-9,17)$.

Vía de administración: la warfarina es completamente absorbida por VO, con una vida plasmática de 42 horas.

Interacción medicamentosa: diferentes drogas alteran su efecto (15) (ver tabla 1).

Presentación:

- Warfarina: coumadín, tabletas de 1, 2,5 y 5 mgfrasco x 20 comprimidos

- Warfarina amorfa: tabletas por $5 \mathrm{mg}$.

\section{Complicaciones:}

- La warfarina cruza la barrera placentaria, por tanto durante la sexta a la décima semanas de gestación pueden producir la embriopatía warfarínica caracterizada por: hipoplasia del cartílago nasal, alteraciones óseas (condrodisplasia punteada) alteraciones oftalmológicas y retardo en el crecimiento intrauterino. En el segundo y tercer trimestres pueden producir alteraciones a nivel del SNC como: agenesia del cuerpo calloso, agenesia del cerebelo, atrofia óptica y atrofia cerebral. Después de las

\section{Tabla 1 \\ INTERACCION CON CUMARINICOS}

\begin{tabular}{lll} 
Potencian acción & Pueden potenciar & Antagonizan \\
Esteroides & & \\
anabólicos & Aminoglicósidos & Barbitúricos \\
Aspirina & Ampicilina & Fenitoína \\
Cloramfenicol & Cefalosporinas & Carbamazepina \\
Trimetropín sulfa & Acido nalidíxico & Glutetimida \\
Neomicina & Antidepresivos & \\
Tetraciclina & tricíclicos & Mercaptopurina \\
Sulfinpirazona & Ciclofosfiramina & Vitamina K \\
Clofibrato & Diclofenac & Antiácidos \\
Clorpromazina & Indometacina & Antihistamínicos \\
Cimetidina & Oxicanes & Griseofulvina \\
Danazol & Profen & Rifampicina \\
Disulfirán & Diazóxido & Primidona \\
Ketoprofeno & Iconazoles & Alcohol \\
Acido mefenámico & Dextropropoxifeno & Algunos vegetales \\
Naproxen & Propiltiouracilo & \\
Oxifenbutazona & Sulfonamidas & \\
Quinidina & Tolbutamida & \\
\hline
\end{tabular}

Pirazolona 
36 semanas de gestación se asocian con hemorragias fetales intracraneanas y retroplacentarias $(17,36)$.

- Hemorragia materna importante en el $20 \%$ de los casos

- Vasculitis alérgica con hemorragias o necrosis masiva del tejido graso (rara)

- Otras: vómito, diarrea, erupciones, fiebre, ictericia, leucopenia, trombocitopenia y reacciones leucemoides.

\section{Antídotos:}

En la madre:

- Vitamina K1 (fitonadiona): $5 \mathrm{mg}$ por vía IV restablecen el TP en 6-12 horas. Dosis de 25-50 mg, actúan más rápidamente, pero la paciente se vuelve refractaria a la reanticoagulación durante más o menos dos semanas.

- Transfusión de sangre fresca total o plasma fresco congelado, antagonizan rápidamente los efectos del coumadín.

- Transfusión de Konyne: plasma rico en factores II, VII, IX y X.

En el niño:

- Todo niño debe recibir luego del parto $1 \mathrm{mg}$ de vitamina $\mathrm{K} 1 \mathrm{IM}$

- Administrar $10 \mathrm{mg} / \mathrm{kg}$ de plasma fresco congelado si: el niño presenta signos de hemorragia, si la gestación es menor de 35 semanas y si el parto ha sido instrumentado y difícil.

Exámenes básicos: hematocrito y hemoglobina, plaquetas, TP-INR.

Esquemas: dosis bajas de $1 \mathrm{a} 5 \mathrm{mg} /$ día de coumadín (INR de 1,5) se han ensayado como tromboprofilaxis con buenos resultados. Los esquemas son:

- Pacientes embarazadas con inserción de válvulas cardíacas mecánicas. Es la droga más usada en Estados Unidos con este propósito. Tiene las ventajas de ser efectiva por VO y de mantener un nivel de anticoagulación estable por períodos largos. Tiene como desventajas lo antes anotado $(17,36)$.

Ocurrida la concepción, el coumadín se sustituye por heparina, la cual no atraviesa la placenta. Esta se continúa hasta las 14-16 semanas, época en la cual se reanudan los cumarínicos (si no se ha de continuar con la heparina, advirtiendo riesgos a la paciente). A las 38 semanas se suspende el coumadín y se vuelve a la heparina. La paciente mostrará un TP normal a las 72 horas de suspenderse el coumadín, pero el feto seguirá anticoagulado durante 7 a 10 días más. Se debe continuar la heparina durante el resto del embarazo y puerperio inmediato (recordar que los cumarínicos no alcanzan un nivel suficiente de anticoagulación hasta los tres o cuatro días de iniciados).

- En los demás casos mencionados de profilaxis con heparina, cuando la paciente no puede autoadministrarse la droga o es alérgica a ella, advirtiéndole a la paciente sobre los riesgos potenciales, bajos pero reales del coumadín.

Medidas mecánicas: la utilización de medias de gradientes de presión y la deambulación precoz han demostrado una prevención efectiva y económica de la ETE. Tales conductas previenen la estasis venosa y activan el sistema fibrinolítico.

\section{Tratamiento de la ETE}

Heparina estándar: actualmente, las heparinas son consideradas los anticoagulantes de elección durante el embarazo, veamos:

Anticoagulación anteparto: diagnosticada la ETE, se debe iniciar tratamiento inmediato, así:

Tromboflebitis profunda (TFP): el tratamiento persigue:

- Prevenir su progreso

- Prevenir el desarrollo de EP

- Disminuir el edema y el dolor

- Evitar el desarrollo del síndrome postflebítico.

Para lograr lo anterior, se deben instaurar las siguientes medidas:

- Reposo absoluto con elevación de la extremidad, evitando angulaciones de la misma (la deambulación se permite cinco a siete días después, siempre y cuando no exista dolor importante).

- Paquetes tibios en el trayecto de las venas afectadas.

- Vendaje elástico compresivo, cuando la paciente lo tolere

- Anticoagulación: se inicia heparina, la cual previene la extensión del trombo ya formado y ayuda a que los mecanismos fibrinolíticos participen en la digestión de éste. Además, la heparina es antiinflamatoria y disminuye la degranulación de los mastocitos y la liberación de serotonina. La dosis inicial es de $5.000 \mathrm{U}$, seguida de 1.000 a $1.600 \mathrm{U} /$ hora en infusión venosa continua. Se debe realizar control de TPTA cada cuatro horas, hasta llevarlo a 1,5 a 2,5 veces el control inicial; una vez ajustado, se realiza cada cuatro horas del primer día y luego diario (15-16).

El tratamiento IV se mantiene en promedio durante 10 días, seguido de heparina subcutánea (7.500-10.000 U cada 12 horas) manteniendo el TPTA en 1,5 veces el normal, sobre todo en el tercer trimestre, época en que es más probable la recurrencia (37).

En casos en que se use la warfarina (coumadín): simultáneamente con la heparina se inicia el coumadín a razón de $5 \mathrm{mg} /$ día, no siendo necesario administrar dosis de carga. A las 48 horas del inicio del coumadín, se solicita TP diario para ajustar la dosis de la droga, hasta cuando el TP esté en el rango de 1,3 a 1,6 (valores por encima de 2, sólo incrementan el sangrado) o el INR esté entre 2 y 3 (INR es igual a la relación del TP observado con respecto a un control o TP de referencia, que se obtiene usando una tromboplastina suministrada por la OMS), tiempo en el cual se suspende la heparina. Luego el TP o INR se solicita una o dos veces por semana.

La duración del tratamiento varía entre 8 y 12 semanas, $(9,15-16)$ ya que experimentalmente se ha visto que la endotelización del coágulo ocurre entre 7 y 10 días y que la adhesión a la pared del vaso dura de 1 a 2 semanas. Además, hay un $\$ \%$ de recurrencia dentro de los primeros 9 meses del episodio agudo. En pacientes con deficiencia de AT-III, proteína C o S y en casos de TFP recurrente, el tratamiento se mantiene indefinidamente.

Embolismo pulmonar $(E P)$ : se debe instaurar tratamiento precoz. Si se produce paro cardíaco, realizar masaje externo intenso, lo que permite a veces fragmen- 
tar y desplazar el émbolo. Se debe administrar oxígeno y tratar la hipotensión con dopamina $(2-10 \mathrm{mcg} / \mathrm{kg} / \mathrm{minu}-$ to) o dobutamina. Si persiste la hipotensión se debe iniciar terapia fibrinolítica y si no se obtiene mejoría, se debe realizar embolectomía.

Anticoagulación: se inicia una dosis de carga de heparina de 10.000 a $15.000 \mathrm{U}$ y luego se continúa en la misma forma que se utiliza para la TFP. La duración del tratamiento es de 3 a 6 meses, recurriendo a la interrupción de la vena cava inferior en casos en que la anticoagulación esté contraindicada o cuando a pesar de la anticoagulación, el tromboembolismo persista en forma activa (15-16).

Anticoagulación y parto: la pérdida de sangre por los efectos de la heparina en el momento del parto, dependen de:

- Dosis, vía y tiempo de administración

- Magnitud de las incisiones y lasceraciones existentes

- La calidad de la retracción uterina e intensidad de las contracciones (una vez expulsados el feto y la placenta) y

- Otros defectos de la coagulación

Las experiencias en el Parkland Memorial Hospital y otras instituciones, demuestran que la pérdida de sangre en los casos de parto vaginal, no aumenta significativamente si la episiotomía no es muy profunda o no se hace, si no hay desgarros en el canal blando del parto y si hay una buena y precoz contracción uterina. La hemostasia uterina no se modifica por la heparina.

Si el TPTA es mayor de 60 segundos durante el expulsivo, se utilizará protamina para disminuir el sangrado. Si se proyecta colocar anestesia conductiva, se aplica la dosis por vía SC al inicio del trabajo de parto y antes de colocar el catéter se comprueba que el TPTA esté normal o cerca. La dosis siguiente de heparina se coloca una vez retirado el catéter.

Si la paciente recibe coumadín, las fuerzas del parto pueden inducir una grave hemorragia en el feto; por tanto se debe administrar vitamina K1 IV lenta, a la dosis de 10 $\mathrm{mg}$. Como vimos antes, los niveles de los factores de coagulación vitamina $\mathrm{K}$ dependientes aumentarán a un nivel seguro en unas ocho horas en la madre y menos rápidamente en el feto.

Anticoagulación y puerperio: lo antes posible en el postparto, la paciente debe recibir la siguiente dosis de heparina SC, ya que sólo en dos-cuatro horas, logra un nivel terapéutico en plasma. La dosis será de 5.000 U cada 12 horas por vía SC. El coumadín se inicia a los cuatrosiete días de la heparina. Se aconseja como profilácticas las medias elásticas hechas a la medida que lleguen hasta la cintura; luego hasta la rodilla, de por vida.

Anticoagulación y aborto: el tratamiento de la TFP con heparina, no impide la terminación de la gestación con un legrado cuidadoso. La heparina se administra al final de la intervención.

En caso de cesárea: es probable una hemorragia grave, si se administra heparina a dosis terapéuticas 72 horas previas a la cesárea luego de ese tiempo, el riesgo disminuye, siendo mínimo a la semana. La mujer con EP reciente que requiera cesárea representa un grave problema; la cesárea y la ligadura de la vena cava inferior (VCI) y de la vena ovárica izquierda mejorarán su pronóstico (38).

Heparinas de bajo peso molecular (HBPM): como vimos antes, la droga más usada para el tratamiento de la ETE durante el embarazo es la enoxaparina (clexane). Esta se administra a razón de $60-80 \mathrm{mg}$ cada 12 horas por vía SC durante 10 días. La dosis por inyección es de un $\mathrm{mg} / \mathrm{kg}=100$ UI anti-Xa/kg. Luego se continúa con dosis profilácticas, generalmente $40 \mathrm{mg} / \mathrm{día}$ en una sola inyección, durante el resto del embarazo, parto y puerperio (se describe administración por períodos de 6 semanas a 6 meses).

Los trabajos recientes realizados con estas drogas en TFP no complicada, posiblemente cambiarán la historia natural de la hospitalización de las pacientes; en el EP aún no existen trabajos que avalen el tratamiento ambulatorio $(9,23,25,27-34)$.

Terapia trombolítica: los agentes fibrinolíticos son drogas que pueden disolver un trombo preformado de fibrina dentro de un vaso sanguíneo. Son útiles en el tratamiento de la RFP proximal y del EP, cuando se aplican en los primeros cinco días de aparición de los síntomas. Son costosos y sólo deben ser aplicados por personal experto en su manejo. Están contraindicados durante el embarazo, trabajo de parto y primeros 10 días del puerperio $(9,15)$.

Las dosis son: para la estreptokinasa, $250.000 \mathrm{U}$ en infusión durante 30 minutos, seguidas de $100.000 \mathrm{U}$ por hora durante $48-72$ horas. Para la uroquinasa, $4.400 \mathrm{U} / \mathrm{kg}$ de peso en infusión durante 15 minutos, seguidos de $4.400 \mathrm{U} / \mathrm{kg} / \mathrm{hora}$. Para el t-PA (activador tisular del plasminógeno) la dosis será de $0,5 \mathrm{mg} / \mathrm{kg} /$ hora durante 4 horas como dosis total. La principal complicación es la hemorragia. Cuando hay necesidad de neutralizar urgentemente la fibrinólisis, algunos utilizan el ácido epsilón aminocaproíco (100 $\mathrm{mg} / \mathrm{kg}$ de peso) o el ácido transnesánico $(10 \mathrm{mg} / \mathrm{kg}$ de peso).

El control de su uso se debe hacer con: fibrinógeno, TP, TPTA, tiempo de trombina y tiempo de lisis total de euglobulinas (previamente y durante la infusión) $(9,15)$.

Trombosis venosa pélvica (TVP): diferentes tratamientos médicos y quirúrgicos se han utilizado en la TVP, pero ninguno de estos esquemas representan investigaciones controladas y prospectivas.

Como se vio antes, la TVP incluye dos síndromes clínicos diferentes: TAVO y fiebre enigmática. Basados en datos retrospectivos, es posible establecer ciertos principios generales para el manejo de la TVP, así:

-En la mayoría de las pacientes la injuria bacteriana al endotelio venoso, ha sido un importante mecanismo en el inicio del proceso tromboembólico.

- Se debe iniciar terapia anticoagulante al realizar el diagnóstico de TVP

Por tanto, la administración de heparina (esquema antes visto en infusión IV por 10 días, seguido de coumadín por tres meses en el caso de la TAVO) y de antibióticos de amplio espectro, debe ser el primer paso en el manejo.

La laparotomía exploradora (LE) está indicada cuando el diagnóstico es dudoso o cuando la paciente no responde al tratamiento médico. Varios reportes informan de LE por posible ruptura apendicular, absceso 
pélvico o torsión de ovario, encontrándose únicamente un trombo extenso en una o ambas venas ováricas. Estas pacientes se cerraron y se les inició terapia con heparina, con recuperación completa.

La controversia que no ha sido resuelta aún, es qué procedimiento debe realizarse en las pacientes que no responden al tratamiento médico. Se han propuesto:

- Ligadura bilateral de venas ováricas y de VCI

- Ligadura unilateral de una vena con o sin ligadura de VCI

- Excisión de vena infectada con o sin ligadura de la vena contralateral y de la VCI.

Brown y Munsick proponen ligadura de venas infectadas y ligadura de VCI únicamente cuando el trombo de una vena se extiende dentro de los grandes vasos. También debe realizarse ligadura de VCI en caso de embolia pulmonar recidivante (procedente de miembros inferiores o de pelvis) y en quienes no responden a más medidas conservadoras quirúrgicas.

El sitio de la ligadura debe ser por debajo del nivel de las venas renales, pero por encima de la entrada de la vena ovárica derecha; además de la ligadura de le vena ovárica izquierda por debajo de su entrada en le vena renal izquierda. Se han utilizado también con buenos resultados, la inserción de un filtro en el interior de la VCI o la aplicación de grapas serradas de teflón (38).
Teóricamente las venas infectadas representan un absceso localizado y por tanto deberían ser excisionadas. No obstante, Maull y Robinson demuestran que la disección y escisión de la vena ovárica puede ser extremadamente difícil, debido a la marcada inflamación y edema. Por tanto, la ligadura de los vasos afectados más la anticoagulación son suficientes para prevenir la propagación de los trombos y émbolos sépticos recurrentes la antibióticoterapia y las defensas del huésped, deben resolver la infección perivascular localizada.

Al realizar ligadura de la vena ovárica y de la VCI, no es necesario realizar anexohisterectomía abdominal, a menos que haya compromiso concomitante en estos órganos (endomiometritis, absceso pélvico, infarto ovárico bilateral). Robinson estableció que después de la ligadura de los vasos pélvicos mayores, se desarrolla una intensa circulación colateral que produce un adecuado drenaje de la pelvis, la cual está dada por: el plexo venoso invertebral, el plexo venoso lumbar, las venas superficiales y profundas de la pared anterior del abdomen, el plexo hemorroidal y el sistema de la vena porta. No obstante, puede haber morbilidad asociada a la ligadura de las venas ováricas y de la VCI, así: edema, síndrome postflebítico definitivo, menoscabo de la fertilidad y mayores complicaciones intra y perioperatorias (mortalidad, paro cardíaco, etc.) $(2,38)$.

\section{BIBLIOGRAFIA}

1. Brandt JT. Conceptos actuales sobre coagulación. Clínicas Obstétricas y Ginecológicas. 1985; 1(1): 3-16.

2. Duff $P$ and Gibbs RS. Pelvic vein trombophebitis: diagnostic dilema and therapeutic challenge. Obstetrical and Gynecological Survey. 1983; 38(6): 365-373.

3. Rutherford SE and Phelan JP. Tromboembolic disease in pregnancy. Clinics in Perinatology 1986; 13(4): 719-739.

4. Clarke - Pearson DL. Variables associated with postoperative deep venous thrombosis: a prospective study of 411 gynecology patients and creations of a pronostic model. Obstetrics and Gynecology. 1987; 69(2): 146-450.

5. Prevention of venous thrombosis and pulmonary embolism: consensus conference (1: 1986: Bethesda) Jama 1986; 256(6): 744-749.

6. Hawiger J. Human pathology: symposium on hemostasis: molecular and cellular pathology. Formation and regulation of platelet and fibrin hemostatic plug. 1987; 18(2): 111-122.

7. Zimmerman TS and Ruggeri Zaverio M. Human pathology: symposium on hemostasis: mollecular and cellular pathology. Von Willebrand Disease 1987; 18(2): 140-152.

8. Castillo CR., Ordinas BA., Reverter Calatayud JC y otros. Enfermedades de la hemostasia. En: Farreras Valenti P-Rozamn C. Medicina Interna. Madrid. Ed. Mosby, Doyma Libros, tercera edición; 1995; 1770-1804.

9. Sistema sanguíneo. En: Isaza M. Carlos A. Isaza M, Gustavo, Fuentes G. Jesualdo, Marulanda M. Tulio. Fundamentos de farmacología en terapéutica. Pereira Ed. Postergrath, tercera edición; 1996; 439-461.

10. O'Reilly Robert A. Fármacos utilizados en los trastornos de la coagulación. En: Katzung Bertram G. Farmacología básica y clínica. México D.F. - Santafé de Bogotá. Ed. El Manual Moderno, quinta edición; 1994; 579-593.

11. Rosemberg R and Baver KA. Human pathology: symposium on hemostasis: molecular and cellular pathology. Thrombosis in inherited deficiences of antithrombin, Protein C and Protein S. 1987; 18(3): 253-262.

12. Schafer Andrew I. The hypercoagulable states. Annals of Internal Medicine. 1985; 102(6): 814-828.

13. Munsick RA. and Gillanders LA. A review of the syndrome of puerperal ovarian vein thrombophlebitis. Obstetrical and Ginecological Survey. 1981; 36(2): 57-66.
14. Alteraciones hematológicas durante el embarazo. Trastornos de la coagulación. En: Arias Fernando. Guía práctica para el embarazo y el parto de alto riesgo. Madrid (España). Ed. Mosby Doyma Libros, segunda edición; 1994; 260-266.

15. Tobón Acosta LI. Enfermedad tromboembólica venosa. En: Actualización en Medicina Interna: Medellín- Colombia - Editorial Universidad de Antioquia, primera edición; mayo 1991; 229-239.

16. Gómez I LF. Tromboembolismo venoso. En: Actualización en medicina Interna. Medellín-Colombia. Editorial Universidad de Antioquia, primera edición; julio 1996; 68-74.

17. Weiner Carl P: Coagulopatías obstétricas. Diagnóstico y tratamiento de la enfermedad tromboembólica durante el embarazo. Clínicas Obstétricas y Ginecológicas. 1985; 1: 131-144.

18. Majerus PW., Broze GJ., Miletich JP y Tollefsen DM. Agentes anticoagulantes, trombolíticos y antiplaquetarios. En: goodman y Gilman. Las bases farmacológicas de la terapéutica. México. Editorial Médica Panamericana, octava edición; 1994; 1271-1289.

19. Collignon F., Frydman A., Caplain H., Ozoux ML et al. Comparison of the pharmacokinetic profiles of three low molecular mass heparins - Dalteparin, Enoxaparin and Nadroparin - Administered subcuytaneously in healthy volunteers (doses for prevention of thromboembolism). Thrombosis and haemostasis. 1995; 73(4): 630640 .

20. Collins R. Reduction in fatal pulmonary embolism and venous thrombosis by perioperative administration of subcutaneous heparin. New England Journal of Medicine. 1988; 318(18): 1162-1173.

21. Hirsh $J$ and Levine MN. Low molecular weight heparin. Blood (the journal of the American Society of Hematology). 1992; 79(1): 1-17.

22. Hirsh J., Raschke R., Warkentin TE., Dalen JE et al. Heparin: mechanism of action, pharmacokinetics, dosing considerations, monitoring, efficacy and safety. Chest: supplement 1995; 108(4): 258S-275S.

23. Fejgin $\mathrm{MD}$ and Lourwood DL. Low molecular weight heparins and their use in obstetrics and gynecology. Obstet. Gynecol. Survey. 1994; 49(6): 424-431.

24. Siragusa S., Cosmi B., Piovella F., Hirsh J et al. Low molecular weight heparins and unfractionated heparin in the treatment of patients with acute venous thromboembolism: results of a Meta-Analysis 1996; 100(3): 269-277. 
25. Gillis S., Shushan A and Eldor A. Use of low molecular weight heparin for prophylaxis and treatment of thromboembolism in pregnancy. Int. J. Gynecol. Obstet. 1992; 39: 297-301.

26. Levine M., Gent M-., Hirsh J., Leclerc J et al. A comparison of low molecular weight heparin. Administered primarily at home with unfractionated heparin administered in the hospital for proximal deep-vein thrombosis. The New England Journal of Medicine. 1996; 334(11): 677-681.

27. Villena-Heinsen C., Schmidt W. Prevention of thrombosis with low molecular weight heparin in gynecology. Zentralbl Gynakol. 1995; 117(6): 289-292.

28. Nelson-Piercy C. Low molecular weight heparin for obstetric thromboprophylaxis. Br. J. Obstet. Gynaecol. 1994; 101(1): 6-8.

29. Dulitski M., Pauzner R., Laugevitz P., Pras M et al. Low molecular weight heparin during pregnancy and delivery: preliminar experience with 41 pregnancies. Obstet. Gynecol. 1996; 87(3): 380-383.

30. Slunsky R. General perioperative prevention of thromboembolism in gynecology with low molecular weight heparin: clinical experiences with enoxaparin over 7 years. Zentralbl-Gynakol. 1995; 117(11): 598-601.

31. Wessel N., Gerner T., Grogaard HK. Should oral contraceptives and Postmenopausal hormonal substitution be withdrawn prior to surgery?
A questionnaire study in departments of surgery and gynecology. Tidsskr. Nor. Laege. Foren. 1995; 115(8): 935-937.

32. Kiss H., Egarter C., Asseryanis E., Putz D., Kneussl M. Primary pulmonary hypertension in pregnancy: a case report Am. J. Obstet. Gynecol. 1995; 172(3): 1052-1054.

33. Shiozaki A., Arai T., Tzumi R., Niiva K., Sakuragawa N. Congenital antithrombin III deficient neonate treated with antithrombin III concentrates. Thromb. Res. 1993; 70(3): 211-216.

34. Borstad E., Urdal K., Handeland G., Abildgaard U. Comparison of low molecular weight heparin vs unfractionated heparin in gynecological surgery II: reduced dose of low molecular weight heparin. Acta Obstet. Gynecol. Scand. 1992; 71(6): 471-475.

35. Peterson Carol E. and Kwaan Hau C. Currents concepts of warfarin therapy. Archives Internal Medicine. 1986; 146(3): 581-584.

36. Michael De Swiet. Anticoagulantes en el embarazo. En: Peter Lewis. Farmacología clínica en obstetricia. Buenos Aires. Editorial Médica Panamericana. 1985; 78-84.

37. Ginsberg Jeffrey $S$ and Hirsh Jack. Use of anticoagulants during pregnancy. Chest supplement 1989; 95(2): 156S-160S.

38. Trastornos del puerperio distintos de la infección puerperal. En: Jack A Pritchard, Paul C. Macdonald, Norman F. Gent. Williams Obstetricia. Barcelona (España). Salvat editores, tercera edición española. 1986; 709-721. 